\title{
Light-Struck Taste in White Wine: Protective Role of Glutathione, Sulfur Dioxide and Hydrolysable Tannins
}

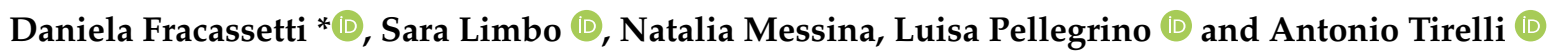 \\ Department of Food, Environmental and Nutritional Sciences, Università degli Studi di Milano, Via G. Celoria 2, \\ 20133 Milan, Italy; sara.limbo@unimi.it (S.L.); nataliamessina.ita@gmail.com (N.M.); \\ luisa.pellegrino@unimi.it (L.P.); antonio.tirelli@unimi.it (A.T.) \\ * Correspondence: daniela.fracassetti@unimi.it
}

check for updates

Citation: Fracassetti, D.; Limbo, S.; Messina, N.; Pellegrino, L.; Tirelli, A. Light-Struck Taste in White Wine: Protective Role of Glutathione, Sulfur Dioxide and Hydrolysable Tannins. Molecules 2021, 26, 5297. https:// doi.org/10.3390/molecules26175297

Academic Editors: Fernando

M. Nunes, Fernanda Cosme and Luís Filipe Ribeiro

Received: 30 July 2021

Accepted: 28 August 2021

Published: 31 August 2021

Publisher's Note: MDPI stays neutral with regard to jurisdictional claims in published maps and institutional affiliations.

Copyright: (c) 2021 by the authors. Licensee MDPI, Basel, Switzerland. This article is an open access article distributed under the terms and conditions of the Creative Commons Attribution (CC BY) license (https:/ / creativecommons.org/licenses/by/ $4.0 /)$.

\begin{abstract}
Light exposure of white wine can cause a light-struck taste (LST), a fault induced by riboflavin (RF) and methionine (Met) leading to the formation of volatile sulfur compounds (VSCs), including methanethiol (MeSH) and dimethyl disulfide (DMDS). The study aimed to investigate the impact of different antioxidants, i.e., sulfur dioxide $\left(\mathrm{SO}_{2}\right)$, glutathione $(\mathrm{GSH})$ and chestnut tannins (CT), on preventing LST in model wine (MW) and white wine (WW), both containing RF and Met. Both MW and WW samples were added with the antioxidants, either individually or in different combinations, prior to 2-h light exposure and they were stored in the dark for 24 months. As expected, the light induced the degradation of RF in all the conditions assayed. Met also decreased depending on the antioxidants added. The presence of antioxidants limited the formation of LST as lower concentrations of VSCs were found in both MW and WW samples. In the latter matrix, neither MeSH nor DMDS were detected in the presence of CT, while only DMDS was found in WW+GSH, $\mathrm{WW}+\mathrm{SO}_{2}+\mathrm{GSH}$ and $\mathrm{WW}+\mathrm{CT}+\mathrm{SO}_{2}$ samples at a concentration lower than the perception thresholds. Considering the antioxidants individually, the order of their effectiveness was $\mathrm{CT} \geq \mathrm{GSH}>\mathrm{SO}_{2}$ in WW under the adopted experimental conditions. The results indicate tannins as an effective enological tool for preventing LST in white wine and their use will be further investigated in different white wines under industrial scale.
\end{abstract}

Keywords: glutathione; sulfur dioxide; hydrolysable tannins; light-struck taste; storage; white wine

\section{Introduction}

Light exposure of white wine, especially at wavelengths spanning from 370 to $450 \mathrm{~nm}$, has a detrimental impact on its sensory characteristics. In particular, photo-induced chemical reactions can be responsible for the wine fault known as light-struck taste (LST) [1,2]. This defect actually arises from two opposite circumstances: the loss of floral and fruity notes [3], and the development of undesired flavors described as cooked cabbage, rotten eggs and onion [4]. The sulfur compounds related to this fault are methanethiol (MeSH) and dimethyl disulfide (DMDS) that are generated through the reaction between riboflavin (RF), a highly photo-sensitive vitamin, and methionine (Met), a sulfur-containing amino acid [5]. Two photo-oxidative mechanisms have been described, both involving RF. In the Type II mechanism, the excited RF transfers the excess of energy to molecular oxygen; as a consequence, singlet oxygen is generated, a very unstable, electrophilic species, capable of reacting with many compounds, including amino acids [6,7]. Once RF is reduced, it can reduce oxygen and return to its ground state $[7,8]$. In the Type I mechanism, when $\mathrm{RF}$ is exposed to light, it reaches the excited triplet state and reacts directly with electron donors, such as phenols and amino acids [9]. In particular, when Met acts as an electron donor, methional is generated. The latter compound is chemically unstable, photo-sensitive and easily decomposes to $\mathrm{MeSH}$ and acrolein through a retro-Michael reaction. Along with the early steps of photo-oxidation, $\mathrm{MeSH}$ can be generated by an alternative pathway that involves a direct cleavage of Met side chain [10]. Moreover, two molecules of MeSH 
can yield DMDS [11]. The olfactory perception thresholds for MeSH and DMDS in wine are $2-10 \mu \mathrm{g} / \mathrm{L}$ and $20-45 \mu \mathrm{g} / \mathrm{L}$, respectively, the latter compound being less volatile [12]. Beside the photo-degradation of RF, other photo-induced reactions may involve tartaric acid and its complexes with iron ions [13]. The reactions result in glyoxylic acid formation, which in turn generates xanthylium ions, the species responsible for the browning of white wine [14].

Several varieties of white wine showed the tendency to develop LST. Previous studies showed that the risk of this fault decreases when RF concentration is lower than $50-80 \mu \mathrm{g} / \mathrm{L}$ [15-17]. The content of RF in grapes is too low for triggering LST [18], but it can increase during the fermentation process due to Saccharomyces cerevisiae metabolic activities. Interestingly, the level of RF in wine is strictly dependent on the Saccharomyces strain performing the alcoholic fermentation $[19,20]$. Consequently, beside protecting white wine from the light [2], oenological strategies suitable for limiting the risk of LST occurrence can be the use of low RF-producer yeast strains and RF removal prior to bottling [20]. The latter approach can be achieved by wine treatment with either bentonite $(1 \mathrm{~g} / \mathrm{L})[15,18]$ or active charcoal (at relatively low concentrations, $0.1 \mathrm{~g} / \mathrm{L}$ ) [20]. These adjuvants are capable of removing up to about $70 \%$ of RF. However, the use of active charcoal as well as a high concentration of bentonite should be limited, as they may cause an aroma depletion of wine [18].

An additional oenological strategy for the prevention of LST can be the use of selected phenols. Maujean and Seguin [11] reported that the addition of flavan-3-ols can limit this wine fault, probably because of their light-shielding effect. Recently, the capability of hydrolysable tannins against LST occurrence was shown in model wine as they prevented the formation of sulfur compounds associated with LST [17]. More specifically, the protective effect of tannins can be ascribed to their competition with Met in donating electrons active in the reduction of RF [21]. In addition, Fracassetti and co-authors [17] hypothesized that singlet oxygen can oxidize tannins to quinones capable of binding $\mathrm{MeSH}$; in this way, formation of DMDS is limited and LST resulted less perceived. Prevention of LST in white wine is of particular interest for the winemakers since this fault may cause the recall of bottled wine from the market [9]. As recently showed by Arapitsas and co-authors [22], LST is extremely persistent in wine and it is still perceived one year after the light exposure. However, the evolution of LST in white wine during its shelf life has not been investigated yet in the presence of antioxidant agents that can be commonly added. Among these, sulfur dioxide $\left(\mathrm{SO}_{2}\right)$ is the most widely used, as well as reduced glutathione $(\mathrm{GSH})$ and hydrolysable tannins. GSH is able to reduce $o$-quinones back to cathecols [23]. GSH can also limit the loss of some aromas, prevent the atypical ageing of white wine and slow down the browning during ageing [24]. Among hydrolysable tannins, ellagitannins can protect phenols against oxidation more reactive to molecular oxygen than the native phenols of wine due to their large number of hydroxyl groups [25,26]. Even if tannins show a preventative effect against the appearance of LST [17], their addition in sparkling wine promoted the formation of sotolon, a marker of atypical ageing [27]. To the best of our knowledge, the effects of these antioxidants against LST have been not investigated. Major unanswered questions related to their use are (i) how a white wine susceptible to LST may change when exposed to light during the storage, and (ii) whether the developed LST persists over time.

Based on these questions, this study aimed to evaluate LST in a simple model wine solution (MW) and in a white wine (WW), both containing RF and Met, when initially exposed to light for a defined time and then stored in the dark for 24 months. The possible protective effect against the LST of the selected antioxidants, including $\mathrm{SO}_{2}, \mathrm{GSH}$ and chestnut tannins (CT) was studied, by adding them, either individually or in different combinations, to both MW and WW. 


\section{Results and Discussion}

The effects of selected antioxidant additives, namely $\mathrm{SO}_{2}, \mathrm{GSH}$ and $\mathrm{CT}$, added individually or in combination, were evaluated in both MW and WW after 24-month storage in the dark with and without a discreet exposure to light $(2 \mathrm{~h})$ prior the storage. The planned experiments would simulate the possible short-term light exposure of wine after bottling in a winery or on the shelf of a store, followed by the storage in the dark condition before commercialization or after purchase.

The amounts of GSH (average amount added: $50 \pm 4 \mathrm{mg} / \mathrm{L}$ ) and $\mathrm{SO}_{2}$ (average amount added: $25 \pm 3 \mathrm{mg} / \mathrm{L}$ ) were chosen based on the results of a previous study [28]. The addition of GSH took into account the possible residual content of GSH in wine that can be up to $30 \mathrm{mg} / \mathrm{L}$ [29] and the supplementation allowed by the International Organization of Vine and Wine (OIV) (20 mg/L) [30]. The addition of RF (200 $\mathrm{gg} / \mathrm{L})$ approaches the amounts $(150 \mu \mathrm{g} / \mathrm{L}$ [16] or even higher) that can occur in wine depending on the yeast strain performing the fermentation [20], while that of Met (4 mg/L) corresponds to the average amounts in wine (3-5 mg/L) [13,31,32]. Hydrolysable tannins showed the ability to prevent LST in model wine when added at $40 \mathrm{mg} / \mathrm{L}$ level [17]. A slightly higher concentration of $50 \mathrm{mg} / \mathrm{L}$ was adopted in the present study in order to further prevent the appearance of LST without promoting bitterness and astringency [33]. Since polyphenols can be involved in the oxidative pathways generating sotolon [27], a marker of atypical ageing of white wine, its presence was also considered.

\subsection{Additives and Storage: Effects in Model Wine Solution}

\subsubsection{Storage in the Dark without Light Exposure}

The effect of the tested antioxidants, added individually or in different combination, was firstly evaluated in MW samples stored without light exposure. As expected, RF was still present $(193.5 \pm 13.5 \mu \mathrm{g} / \mathrm{L})$, which is not surprising since RF is relatively stable to heat-treatments, dehydration and usual food storage conditions [34,35]. In contrast, this compound is extremely sensitive to visible or UV light. The decrease of Met (concentration added: $4.63 \pm 0.28 \mathrm{mg} / \mathrm{L})$ was from small to negligible $(-2 \%)$ and only occurred in the absence of additives (Table 1). Differently, the decrease of Met was dependent on the additives added and ranged from $-24 \%$ in $\mathrm{MW}+\mathrm{SO}_{2}$ and $\mathrm{MW}+\mathrm{SO}_{2}+\mathrm{GSH}$ samples up to $-100 \%$ in MW+GSH and MW+CT+GSH samples (Table 1). Among compounds expected to arise from the oxidation of Met [36], only Met sulfoxide was found, in accordance with the previous study carried out by NMR [21]. The absence of this compound in MW samples without additives allowed to exclude the possible oxidation of Met by the acidic environment or matrix components. In the presence of $\mathrm{SO}_{2}$, Met sulfoxide could arise from aerobic oxidation of bisulfite, leading to several radical species [37]. Met was completely oxidized into Met sulfoxide in $\mathrm{MW}+\mathrm{GSH}$ and $\mathrm{MW}+\mathrm{SO}_{2}+\mathrm{GSH}$ samples (Table 1). Under our experimental conditions, it seems that GSH behaved as a pro-oxidant instead of an antioxidant, possibly because of its efficiency in scavenging free radicals, thus generating thiyl radicals. The thiyl radical favors the formation of superoxide as well as singlet oxygen [38]. As a consequence, the oxidation of Met to Met sulfoxide could be promoted even because Met is one of the amino acids mainly targeted by singlet oxygen [39]. Consistently, Met sulfoxide was the main product explaining the loss of Met in the samples with added $\mathrm{SO}_{2}$ and GSH, alone or in combination (Table 1). On the contrary, Met sulfoxide did not quantitatively correspond to Met lost in the presence of $\mathrm{CT}$, with or without $\mathrm{SO}_{2}$ and $\mathrm{GSH}$, thus suggesting that compounds other than Met sulfoxide could be generated in these conditions [36].

GSH strongly decreased in all samples and it was not detected in MW+GSH treatment (Table 1). Cys was found in the samples where GSH was present, with the exception of the MW+GSH sample, and likely derived from the hydrolysis of this tripeptide [28] due to the long storage and the acidic environment adopted in this study. 
Little differences were found in TPI that resulted slightly higher, though statistically significant, in the $\mathrm{MW}+\mathrm{CT}+\mathrm{SO}_{2}+\mathrm{GSH}$ sample. Comparable absorbance values at $420 \mathrm{~nm}$ were found in the MW samples added with $\mathrm{CT}$, with or without $\mathrm{SO}_{2}$ and GSH.

The volatile sulfur compounds (VSCs) associated with LST were determined even for the trial without light exposure. None of VSCs, namely MeSH, DMDS and dimethyl trisulfide (DMTS), were detected in MW samples stored in the dark without light exposure. Similarly, no perception of the cooked cabbage note occurred in those samples (data not shown).

\subsubsection{Storage in the Dark after Light Exposure}

No residual RF was found in MW samples exposed to light prior to storage, irrespective of the antioxidant mixture added (data not shown). As observed for the samples stored without light exposure, the decrease of Met was related to the presence of additives, and it ranged between $-41 \%$ in samples without any additives and $-100 \%$ with MW+CT+GSH treatment (Table 1). In terms of Met loss, the impact of light exposure of MW samples was evident in most of the conditions tested. The exceptions were MW+CT and $\mathrm{MW}+\mathrm{CT}+\mathrm{SO}_{2}$ samples, where the Met decrease was comparable in treatments with and without light exposure, and MW+CT+GSH samples, where Met was not revealed after storage (Table 1). Contrarily to what was observed in the absence of light exposure, both Met and GSH were still detected after storage in MW+GSH samples. This behavior is hard to explain; the efficient scavenging activity of GSH and the generated thiyl radicals [38] may participate in the photo-oxidative reactions and limit the oxidation of Met, while these radicals could oxidize Met in dark storage (Table 1). Residual GSH concentrations ranged from $2.39 \pm 0.65 \mathrm{mg} / \mathrm{L}$ to $7.86 \pm 0.63 \mathrm{mg} / \mathrm{L}$ in MW+GSH and MW+CT+GSH samples, respectively (Table 1). To a certain extent, under the adopted experimental conditions, the light exposure seems to limit the degradation/hydrolysis of GSH when added alone or in combination with CT. The scavenger and/or quencher activity of hydrolysable tannins may have a protective effect towards GSH since the residual level of GSH was higher in samples also added with CT. In any case, further investigations are needed in order to clarify GSH reactivity towards Met and its role in photo-degradative mechanisms. The lowest concentrations of Met sulfoxide were found in the CT-added samples, despite the little amounts of residual Met. These results suggest that the formation of Met sulfoxide is lower and Met can go through different oxidative fate [36] in the presence of hydrolysable tannins.

Light exposure showed a negligible effect on TPI in MW samples where CT was added (Table 1); the addition of the other antioxidants did not significantly influence the TPI. Differences were found in the absorbance values at $420 \mathrm{~nm}$ that were significantly higher in $\mathrm{MW}+\mathrm{CT}$ sample, although to a small extent. In comparison with the samples stored in the dark without light exposure (Table 1), the absorbance values at $420 \mathrm{~nm}$ were nearly halved (Table 1). The photo-induced mechanisms did not lead to a browning phenomenon in the experimental conditions adopted, possibly because of the absence of the transition metals, catalyzers of oxidations $[14,40]$. 


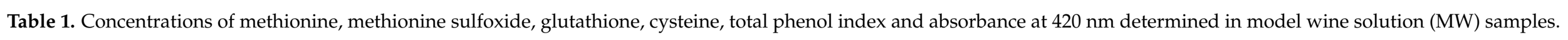

\begin{tabular}{|c|c|c|c|c|c|c|}
\hline \multirow{2}{*}{ Treatment } & Methionine & Methionine Sulfoxide & Glutathione & Cysteine & \multirow{2}{*}{ Total Phenol Index } & Absorbance at $420 \mathrm{~nm}$ \\
\hline & $\mathrm{mg} / \mathrm{L}(\mu \mathrm{mol} / \mathrm{L})$ & $\mathrm{mg} / \mathrm{L}(\mu \mathrm{mol} / \mathrm{L})$ & $\mathrm{mg} / \mathrm{L}$ & $\mathrm{mg} / \mathrm{L}$ & & AU \\
\hline \multicolumn{7}{|c|}{ Samples Stored in the Dark for 24 Months without Light Exposure } \\
\hline MW & $4.52 \pm 0.32^{\mathrm{a}}(30.30)$ & $\mathrm{nd}^{\mathrm{e}}$ & na & na & na & na \\
\hline $\mathrm{MW}+\mathrm{SO}_{2}$ & $3.54 \pm 0.25^{b}(23.74)$ & $0.47 \pm 0.03^{\mathrm{b}}(2.87)$ & na & na & na & na \\
\hline MW+GSH & nd $^{\mathrm{c}}$ & $5.18 \pm 0.36^{\mathrm{a}}(31.34)$ & $\mathrm{Nd}^{\mathrm{c}}$ & $\mathrm{nd}^{\mathrm{c}}$ & na & na \\
\hline $\mathrm{MW}+\mathrm{SO}_{2}+\mathrm{GSH}$ & $3.51 \pm 0.25^{\mathrm{b}}(23.54)$ & $0.85 \pm 0.06^{\mathrm{c}}(5.14)$ & $2.20 \pm 0.11^{\mathrm{a}}$ & $0.46 \pm 0.02^{\mathrm{a}}$ & na & na \\
\hline $\mathrm{MW}+\mathrm{CT}$ & $0.31 \pm 0.02^{\mathrm{d}}(2.07)$ & $0.43 \pm 0.03^{b}(2.63)$ & na & na & $0.948 \pm 0.006^{\mathrm{a}}$ & $0.039 \pm 0.001^{\mathrm{a}}$ \\
\hline $\mathrm{MW}+\mathrm{CT}+\mathrm{GSH}$ & nd ${ }^{c}$ & $0.50 \pm 0.04^{\mathrm{b}}(3.04)$ & $0.28 \pm 0.014^{b}$ & $0.32 \pm 0.02^{b}$ & $0.946 \pm 0.006^{\mathrm{a}}$ & $0.041 \pm 0.002^{a}$ \\
\hline $\mathrm{MW}+\mathrm{CT}+\mathrm{SO}_{2}+\mathrm{GSH}$ & $1.54 \pm 0.11^{\mathrm{e}}(10.29)$ & $1.72 \pm 0.12^{\mathrm{d}}(10.39)$ & $0.24 \pm 0.012^{b}$ & $0.30 \pm 0.01^{b}$ & $0.987 \pm 0.007^{b}$ & $0.043 \pm 0.002^{\mathrm{a}}$ \\
\hline \multicolumn{7}{|c|}{ Samples Stored in the Dark for 24 Months after Light Exposure } \\
\hline MW & $2.71 \pm 0.31^{\mathrm{a}}(18.15)$ & $0.88 \pm 0.73^{\mathrm{b}}(5.34)$ & na & na & na & na \\
\hline $\mathrm{MW}+\mathrm{SO}_{2}$ & $2.50 \pm 0.14^{\mathrm{a}}(16.78)$ & $2.19 \pm 0.06^{\mathrm{a}}(13.28)$ & na & na & na & na \\
\hline MW+GSH & $2.60 \pm 0.58^{a}(17.42)$ & $0.89 \pm 0.47^{\mathrm{b}}(5.37)$ & $2.39 \pm 0.65^{c}$ & $0.31 \pm 0.01^{\mathrm{c}}$ & na & na \\
\hline $\mathrm{MW}+\mathrm{SO}_{2}+\mathrm{GSH}$ & $2.04 \pm 0.08^{b}(13.69)$ & $2.24 \pm 0.06^{\mathrm{a}}(13.58)$ & $2.57 \pm 0.83^{c}$ & $0.33 \pm 0.00^{\mathrm{c}}$ & na & na \\
\hline $\mathrm{MW}+\mathrm{CT}$ & $0.28 \pm 0.07^{\mathrm{c}}(1.85)$ & $0.35 \pm 0.03^{\mathrm{c}}(2.13)$ & na & na & $0.918 \pm 0.006^{\mathrm{a}}$ & $0.028 \pm 0.003^{a}$ \\
\hline $\mathrm{MW}+\mathrm{CT}+\mathrm{GSH}$ & nd ${ }^{d}$ & $0.44 \pm 0.06^{\mathrm{c}}(2.67)$ & $7.86 \pm 0.63^{a}$ & $0.37 \pm 0.04^{b}$ & $0.952 \pm 0.007^{\mathrm{a}}$ & $0.027 \pm 0.002 \mathrm{ab}$ \\
\hline $\mathrm{MW}+\mathrm{CT}+\mathrm{SO}_{2}+\mathrm{GSH}$ & $0.21 \pm 0.04^{\mathrm{c}}(1.39)$ & $0.26 \pm 0.04^{\mathrm{c}}(1.58)$ & $3.99 \pm 1.04^{b}$ & $1.07 \pm 0.02^{\mathrm{a}}$ & $0.936 \pm 0.050^{\mathrm{a}}$ & $0.020 \pm 0.006^{c}$ \\
\hline
\end{tabular}

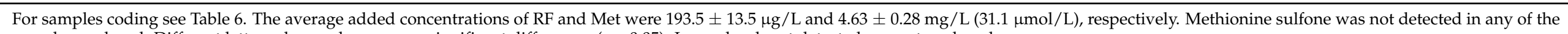
samples analysed. Different letters along column mean significant differences $(p<0.05)$. Legend: nd, not detected; na, not analyzed. 
The concentrations of MeSH and DMDS were influenced by the antioxidant added but were significantly higher in the MW sample without any antioxidants. The addition of all three antioxidants was most effective in MW, as only negligible amounts of MeSH and with no DMDS were found (Table 2).

Table 2. Concentrations ( $\mu \mathrm{g} / \mathrm{L})$ of methanethiol $(\mathrm{MeSH})$, dimethyl disulfide (DMDS) and dimethyl trisulfide (DMTS) in model wine (MW) samples stored in the dark after light exposure.

\begin{tabular}{|c|c|c|c|c|c|c|c|}
\hline \multirow{2}{*}{ Treatment } & \multicolumn{2}{|c|}{ MeSH } & \multicolumn{2}{|c|}{ DMDS } & \multicolumn{2}{|c|}{ DMTS } & \multirow{2}{*}{$\begin{array}{c}\text { Ratio Sulfur } \\
\text { Formed/Met Degraded }\end{array}$} \\
\hline & $\mu \mathrm{g} / \mathrm{L}$ & OAV & $\mu \mathrm{g} / \mathrm{L}$ & OAV & $\mu \mathrm{g} / \mathrm{L}$ & OAV & \\
\hline MW & $10.83 \pm 0.99^{\mathrm{a}}$ & 36.1 & $47.65 \pm 3.86^{\mathrm{a}}$ & $1.1-2.4$ & $64.04 \pm 7.17^{\mathrm{ab}}$ & 640 & 14.05 \\
\hline $\mathrm{MW}+\mathrm{SO}_{2}$ & $1.42 \pm 0.13^{\mathrm{d}}$ & 4.7 & nd & - & $5.97 \pm 0.67^{\mathrm{d}}$ & 59.7 & 0.82 \\
\hline MW+GSH & $1.38 \pm 0.13^{d}$ & 4.6 & $0.67 \pm 0.05^{b}$ & $<0.03$ & $64.94 \pm 7.27 \mathrm{ab}$ & 649 & 7.79 \\
\hline $\mathrm{MW}+\mathrm{SO}_{2}+\mathrm{GSH}$ & $2.93 \pm 0.27^{c}$ & 9.8 & $0.99 \pm 0.08^{b}$ & $<0.05$ & $5.43 \pm 0.61^{\mathrm{d}}$ & 54.3 & 0.87 \\
\hline $\mathrm{MW}+\mathrm{CT}$ & $1.14 \pm 0.10 \mathrm{de}$ & 3.8 & nd & - & $73.52 \pm 8.23^{a}$ & 735 & 4.93 \\
\hline $\mathrm{MW}+\mathrm{CT}+\mathrm{SO}_{2}$ & $6.07 \pm 0.55^{\mathrm{b}}$ & 20.2 & nd & - & $27.16 \pm 3.04^{c}$ & 272 & 2.14 \\
\hline $\mathrm{MW}+\mathrm{CT}+\mathrm{GSH}$ & $0.45 \pm 0.04^{\mathrm{e}}$ & 1.5 & nd & - & $56.28 \pm 6.30^{b}$ & 563 & 3.56 \\
\hline $\mathrm{MW}+\mathrm{CT}+\mathrm{SO}_{2}+\mathrm{GSH}$ & $0.45 \pm 0.04^{\mathrm{e}}$ & 1.5 & nd & - & $0.75 \pm 0.08^{\mathrm{e}}$ & 7.5 & 0.07 \\
\hline
\end{tabular}

The Odor Activity Values (OAVs) were calculated as the ratio between the amount found in the sample and the perception threshold for each volatile sulfur compound. The perception threshold concentrations considered are as follows: MeSH, $0.3 \mu \mathrm{g} / \mathrm{L} ; \mathrm{DMDS}, 20-45 \mu \mathrm{g} / \mathrm{L}$; DMTS, $0.1 \mu \mathrm{g} / \mathrm{L}$ [12]. For samples coding see Table 6. Different letters mean significant differences $(p<0.05)$. Legend: nd, not detected.

This result was in accordance with the outcome of sensory analysis: The perception of the "cooked cabbage" note was negligible (2/9) for the $\mathrm{MW}+\mathrm{CT}+\mathrm{SO}_{2}+\mathrm{GSH}$ sample, while the highest perception (7/9) was in the $\mathrm{MW}+\mathrm{CT}+\mathrm{SO}_{2}$ sample (Figure 1). The formation of DMTS could be dependent on the long storage since it was absent in MW samples with added hydrolysable tannins just after the light exposure as previously observed [17]. DMTS could originate upon storage from the oxidation of methional and MeSH [41] and its formation could be prevented by $\mathrm{SO}_{2}$, as lower levels of DMTS were found in the presence of $\mathrm{SO}_{2}$ (Table 2). Interestingly, considering the sulfur conversion yield (sulfur formed/Met degraded), values lower than 1 were found in the treatments with $\mathrm{SO}_{2}$ alone or in combination with GSH and CT. These findings suggest that in these samples, Met mainly acted as an electron-donor to reduce RF. In the other samples, additional chemical pathways were also involved leading to Met oxidation, i.e., reaction with singlet oxygen, forming Met sulfoxide and other oxidative products [36] as mentioned above.

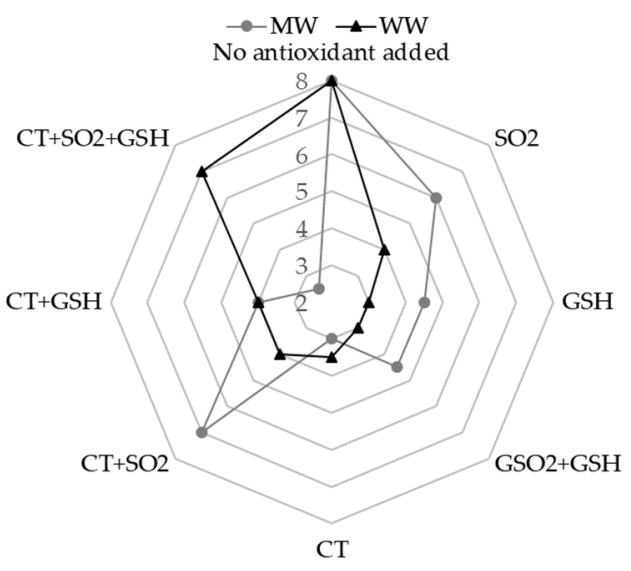

Figure 1. Sensory perception of the descriptor "cooked cabbage" related to the light-struck taste for both model wine solution (MW) and white wine (WW) both stored in the dark after light exposure. Data were obtained from medians of the scores indicated by the judges. For samples coding see to Table 6. Legend: $\mathrm{SO}_{2}$, sulfur dioxide; $\mathrm{GSH}$, glutathione; $\mathrm{CT}$, chestnut tannins. 


\subsection{Additives and Storage: Effects in White Wine}

\subsubsection{Storage in the Dark without Light Exposure}

In all WW samples, RF was still present (177.2 $\pm 4.2 \mu \mathrm{g} / \mathrm{L})$ after 24-month storage in the dark without light exposure, while an overall decrease of Met was observed (Table 3) in the experimental conditions adopted. Such a decrease of Met was small (about $-5 \%$ ) in the $\mathrm{WW}_{0}$ sample (not spiked white wine) whereas, in the additive-spiked WW samples, it ranged from $-26 \%(\mathrm{WW}+\mathrm{GSH})$ to $-59 \%\left(\mathrm{WW}+\mathrm{CT}+\mathrm{SO}_{2}+\mathrm{GSH}\right)$. These data suggest that the degradation of Met could be due to its oxidative deamination [42] as it was limited by GSH and promoted by $\mathrm{SO}_{2}$. The aerobic oxidation of bisulfite, leading to several radical species [37], might cause a higher loss of Met.

Cys content was comparable in all samples and was $3.10 \pm 0.07 \mathrm{mg} / \mathrm{L}$ on average (Table 3). The strong decrease of GSH, observed in all the GSH-spiked samples, did not correspond to an increase of Cys. $\mathrm{SO}_{2}$ did not prevent GSH oxidation since no significant differences were found between $\mathrm{WW}+\mathrm{GSH}$ and $\mathrm{WW}+\mathrm{SO}_{2}+\mathrm{GSH}$ samples (Table 3). On the contrary, CT led to significantly higher concentrations of GSH that persisted in WW samples after 24-month storage in the dark. Such a difference in GSH levels can be ascribed to the ability of CT to consume oxygen [43] due to its galloyl- groups [44], thus protecting GSH against oxidation. The negligible effect of $\mathrm{SO}_{2}$ against GSH oxidation was also revealed in the $\mathrm{WW}+\mathrm{CT}+\mathrm{SO}_{2}+\mathrm{GSH}$ sample whose $\mathrm{GSH}$ concentration was not significantly different from that of the WW+CT+GSH sample.

Slight differences were found in both TPI and flavonoids depending on the different additives tested and their combinations (Table 3). The lowest levels of TPI and flavonoids were found in the presence of both $\mathrm{GSH}$ and $\mathrm{SO}_{2}$. The absorbance values at $420 \mathrm{~nm}$ were significantly lower in the presence of $\mathrm{SO}_{2}$, confirming the efficacy of this antioxidant in protecting the yellow color of white wine [27].

None of the VSCs, namely MeSH, DMDS and DMTS, were detected in this set of samples and, consistently, the perception of the cooked cabbage note was only negligible as the samples were scored 2/9 at maximum (data not shown). This finding indicates that an LST-susceptible wine, even if intentionally, does not develop this fault until it is protected against the light, e.g., by using dark bottles [22]. However, the light exposure of white wine in dark bottles can still have an indirect impact through the increase in temperature. Maury and co-authors [45] found major browning caused by the high level of xanthylium ions present in dark bottles and released due to high temperature. Proper oenological strategies and storage conditions are essential to preserve the wine quality after bottling.

\subsubsection{Storage in the Dark after Light Exposure}

Similar to MW samples, no RF was detected in WW samples independently of the antioxidants tested (data not shown).

Met content decreased in WW samples containing both GSH and $\mathrm{SO}_{2}(-21 \%)$ or $\mathrm{SO}_{2}$ only $(-38 \%)$ (Table 3), suggesting the influence of the antioxidants on photo-degradative mechanisms and their competition with Met in both Type I and Type II pathways [13,17,21].

Changes in the profile of free amino acids in WW samples were found to be dependent on the antioxidants added (Figure A1 in Appendix A), with the exceptions of serine, aspartic acid, isoleucine, valine and lysine whose concentration decreased in all assayed conditions, and alanine, glutamine and phenylalanine showing negligible differences (data not shown). While tryptophan was not detected in any sample, possibly because of a concentration lower than the detection limit, Cys was detected only in WW samples added with GSH that, as already mentioned, can be its parent molecule [28]. For other amino acids, such as histidine and tyrosine, the addition of $\mathrm{SO}_{2}$ and its combination with CT led to a small decrease (Figure A1 in Appendix A). Overall, the decrease of histidine, tyrosine, Met and Cys could be due to the reaction with singlet oxygen, indicating that amino acids other than Met can act as electron donors bringing RF back to its reduced state. Min and Boff [39] reported that singlet oxygen mainly reacts with five amino acids (tryptophan, histidine, tyrosine, Met and Cys). GSH could act as an electron donor in the reduction of 
RF; in fact, even if it decreased up to $88 \%$ in WW samples stored in the dark, GSH contents halved in samples exposed to light in comparison to those stored in the dark (Table 3). Both $\mathrm{CT}$ and $\mathrm{SO}_{2}$ did prevent GSH oxidation since significant differences were found in treatments with combined addition of the different additives (Table 3).

Changes in the profile of free amino acids in WW samples were found to be dependent on the antioxidants added (Figure A1 in Appendix A), with the exceptions of serine, aspartic acid, isoleucine, valine and lysine whose concentration decreased in all assayed conditions, and alanine, glutamine and phenylalanine showing negligible differences (data not shown). While tryptophan was not detected in any sample, possibly because of a concentration lower than the detection limit, Cys was detected only in WW samples added with GSH that, as already mentioned, can be its parent molecule [28]. For other amino acids, such as histidine and tyrosine, the addition of $\mathrm{SO}_{2}$ and its combination with CT led to a small decrease (Figure A1 in Appendix A). Overall, the decrease of histidine, tyrosine, Met and Cys could be due to the reaction with singlet oxygen, indicating that amino acids other than Met can act as electron donors bringing RF back to its reduced state. Min and Boff [39] reported that singlet oxygen mainly reacts with five amino acids (tryptophan, histidine, tyrosine, Met and Cys). GSH could act as an electron donor in the reduction of RF; in fact, even if it decreased up to $88 \%$ in WW samples stored in the dark, GSH contents halved in samples exposed to light in comparison to those stored in the dark (Table 3). Both $\mathrm{CT}$ and $\mathrm{SO}_{2}$ did prevent GSH oxidation since significant differences were found in treatments with combined addition of the different additives (Table 3).

The absorbance values at $420 \mathrm{~nm}$ were lower in WW samples that were exposed to light before the dark storage in comparison to those that were not. Furthermore, a major protective effect on yellow color was observed in the presence of $\mathrm{SO}_{2}(0.061 \pm 0.001 \mathrm{AU})$, GSH $(0.073 \pm 0.000 \mathrm{AU})$ or the combination of the two $(0.071 \pm 0.001 \mathrm{AU})$ (Table 3$)$. In the presence of $\mathrm{CT}$, the absorbance values at $420 \mathrm{~nm}$ were slightly higher $(0.090 \pm 0.006-0.103 \pm$ $0.006 \mathrm{AU}$ ), but still halved compared to the same samples stored in the dark (Table 3 ). These findings differ from previous literature results since a browning increase was reported to be due to the light exposure $[2,14,40]$. Such a difference could depend on the wine tested in the study or the light source employed for the light exposure. We could expect the metal-mediated oxidative phenomena to occur since both iron and copper were present in WW although at low concentrations $(1.95 \mathrm{mg} / \mathrm{L}$ and $0.24 \mathrm{mg} / \mathrm{L}$ for iron and copper, respectively). Further investigation is needed to better clarify this aspect.

The content of both MeSH and DMDS varied remarkably in WW samples, depending on the antioxidants added (Table 4), and both compounds were not detected in WW+CT sample. No DMTS was detected in all samples. No MeSH was found and the DMDS concentration was lower than the perception threshold in WW+GSH, WW+SO $\mathrm{S}_{2}+\mathrm{GSH}$ and $\mathrm{WW}+\mathrm{CT}+\mathrm{SO}_{2}$ (Table 4). This result was also supported by the sensory analysis indicating no significant differences between the above-mentioned samples (Figure 1). The MeSH concentration was higher than the respective perception threshold in WW (Odor Activity Values (OAVs) 18.9-94.5), $\mathrm{WW}+\mathrm{SO}_{2}(\mathrm{OAVs}$ 1.2-5.9) and WW+CT+GSH (OAVs 1.4-7.0) samples. DMDS led to an OAV up to 1.3 only in samples containing all three antioxidants investigated. We cannot exclude that the antioxidant activity of $\mathrm{SO}_{2}$, when present at concentrations close to $100 \mathrm{mg} / \mathrm{L}$, may limit the ability of hydrolysable tannins to work against LST formation, possibly because $\mathrm{SO}_{2}$ can reduce the quinones back to phenols avoiding the thiol group of MeSH to perform this reduction [46]. Our results confirm LST to be an irreversible fault that can be perceived in wine stored in the dark for longer than one year [22]. 
Table 3. Concentrations of methionine, glutathione, cysteine, flavonoids, total phenol index and absorbance values at $420 \mathrm{~nm}$ determined in white wine (WW) samples.

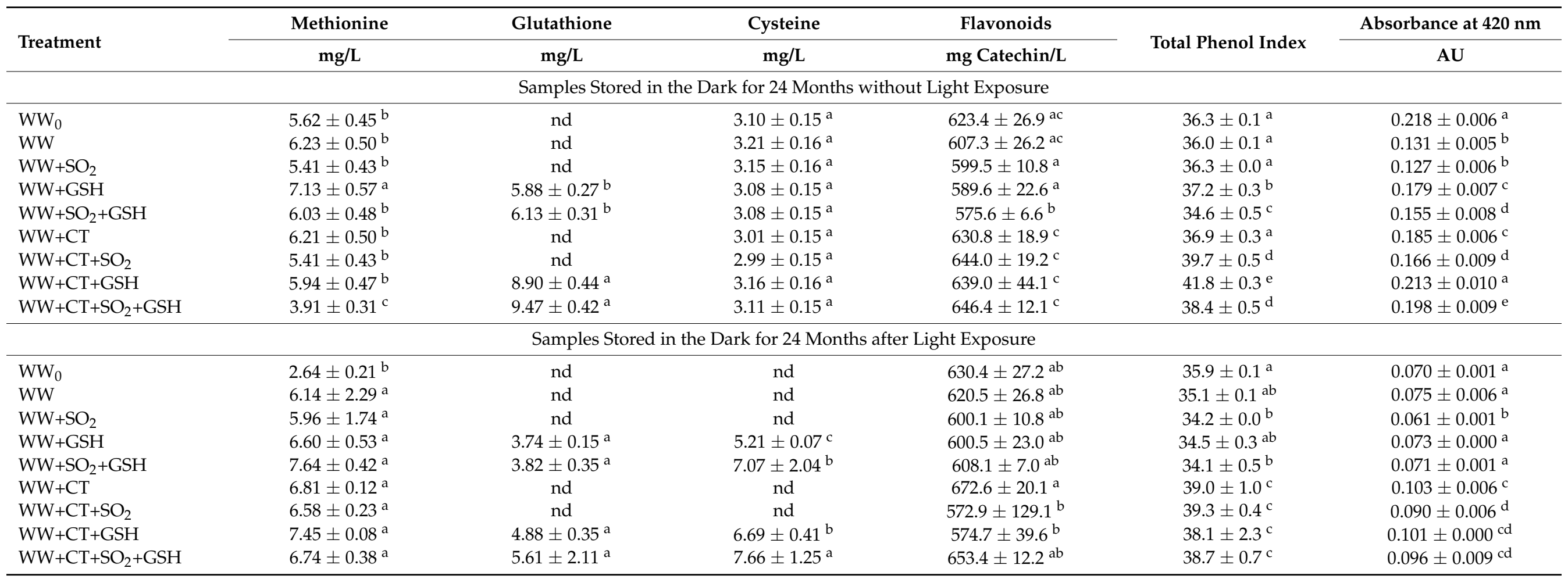

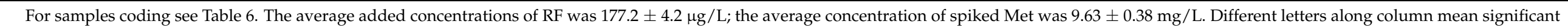
differences $(p<0.05)$. Legend: nd, not detected; $\mathrm{WW}_{0}$ : glutathione- and riboflavin-free white wine, Met concentration was $5.90 \pm 0.35 \mathrm{mg} / \mathrm{L}$. 
Table 4. Concentrations ( $\mu \mathrm{g} / \mathrm{L})$ of methanethiol $(\mathrm{MeSH})$ and dimethyl disulfide (DMDS) determined in white wine (WW) samples.

\begin{tabular}{|c|c|c|c|c|c|}
\hline \multirow{2}{*}{ Treatment } & \multicolumn{2}{|c|}{ MeSH } & \multicolumn{2}{|c|}{ DMDS } & \multirow{2}{*}{$\begin{array}{c}\text { Molar Ratio Sulfur } \\
\text { Formed/ Met Degraded }\end{array}$} \\
\hline & $\mu \mathrm{g} / \mathrm{L}$ & OAV & $\mu \mathrm{g} / \mathrm{L}$ & OAV & \\
\hline WW & $189.09 \pm 17.21^{\mathrm{a}}$ & $18.9-94.5$ & $2.83 \pm 0.23^{d}$ & $<0.14$ & 17.09 \\
\hline $\mathrm{WW}+\mathrm{SO}_{2}$ & $11.80 \pm 1.07^{\mathrm{b}}$ & $1.2-5.9$ & $2.48 \pm 0.20^{d}$ & $<0.12$ & 1.21 \\
\hline WW+GSH & nd & - & $1.34 \pm 0.11^{\mathrm{d}}$ & $<0.07$ & 0.14 \\
\hline $\mathrm{WW}+\mathrm{SO}_{2}+\mathrm{GSH}$ & nd & - & $4.82 \pm 0.39^{c}$ & $0.11-0.24$ & 0.77 \\
\hline $\mathrm{WW}+\mathrm{CT}$ & nd & - & nd & - & 0.00 \\
\hline $\mathrm{WW}+\mathrm{CT}+\mathrm{SO}_{2}$ & nd & - & $18.86 \pm 1.53^{b}$ & $0.4-0.9$ & 1.96 \\
\hline $\mathrm{WW}+\mathrm{CT}+\mathrm{GSH}$ & $14.03 \pm 1.28^{b}$ & $1.4-7.0$ & $16.69 \pm 1.35^{b}$ & $0.4-0.8$ & 4.43 \\
\hline $\mathrm{WW}+\mathrm{CT}+\mathrm{SO}_{2}+\mathrm{GSH}$ & nd & - & $25.18 \pm 2.04^{\mathrm{a}}$ & $0.6-1.3$ & 2.76 \\
\hline
\end{tabular}

No volatile sulfur compounds were revealed in the $\mathrm{WW}_{0}$ sample (glutathione- and riboflavin-free white wine, no Met added). The Odor Activity Value $(\mathrm{OAV})$ was calculated as the ratio between the amount found in the sample and the perception threshold of the volatile sulfur compound. The perception threshold concentrations considered are as follows: MeSH, 2-10 $\mu \mathrm{g} / \mathrm{L}$; DMDS, 20-45 $\mu \mathrm{g} / \mathrm{L}$ [12]. For samples coding see Table 6. Different letters mean significant differences $(p<0.05)$. Legend: nd, not detected.

Sotolon is a compound mainly associated with atypical (or oxidative) white wine ageing [47]. A previous study showed that the use of phenol-based preparations to replace $\mathrm{SO}_{2}$ could cause an increase of sotolon content [27]. In the experimental conditions adopted here, negligible amounts of sotolon were detected in all tested samples (Table 5). The highest concentrations of sotolon were observed in the WW sample $(3.96 \pm 0.72 \mu \mathrm{g} / \mathrm{L})$ followed by WW+CT $+\mathrm{SO}_{2}+\mathrm{GSH}(2.53 \pm 0.53 \mu \mathrm{g} / \mathrm{L})$. In any case, the concentration of sotolon in all WW samples was lower than its olfactory perception threshold $(7-8 \mu \mathrm{g} / \mathrm{L})$ in white wine [48] indicating that none of the tested antioxidants, singularly or in combination, were responsible for atypical ageing.

Table 5. Concentrations $(\mu \mathrm{g} / \mathrm{L})$ of sotolon determined in white wine $(\mathrm{WW})$ samples.

\begin{tabular}{cc}
\hline Treatment & Sotolon \\
\hline $\mathrm{WW}_{0}$ & $3.96 \pm 0.72^{\mathrm{a}}$ \\
$\mathrm{WW}$ & $1.06 \pm 0.07^{\mathrm{c}}$ \\
$\mathrm{WW}+\mathrm{SO}_{2}$ & nd \\
$\mathrm{WW}+\mathrm{GSH}$ & nd \\
$\mathrm{WW}+\mathrm{SO}_{2}+\mathrm{GSH}$ & nd \\
$\mathrm{WW}+\mathrm{CT}$ & trace \\
$\mathrm{WW}+\mathrm{CT}+\mathrm{SO}_{2}$ & $0.59 \pm 0.02^{\mathrm{d}}$ \\
$\mathrm{WW}+\mathrm{CT}+\mathrm{GSH}$ & $0.85 \pm 0.07^{\mathrm{c}}$ \\
$\mathrm{WW}+\mathrm{CT}+\mathrm{SO}_{2}+\mathrm{GSH}$ & $2.13 \pm 0.36^{\mathrm{b}}$
\end{tabular}

For samples coding see Table 6. Different letters mean significant differences $(p<0.05)$. Legend: nd, not detected; $\mathrm{WW}_{0}$ : glutathione- and riboflavin-free white wine, no Met added.

The overall profile of volatile compounds (VOCs) was considered in WW samples exposed to light before storage. Thirty VOCs were detected corresponding to 3 acids, 8 alcohols and 19 esters (Figure A2 in Appendix A). Differences were found in relation to the antioxidants added. The significant increase occurring in the presence of antioxidants were related to nonanoic acid ethyl ester, 3-henex-1-ol and 2,4-hexadienoic ethyl ester in particular where CT was added. These compounds are associated with green and fat, grass and apple and peach notes, respectively. The two esters, isopropyl 3,4 hexadionate and decanoic acid ethyl ester, both responsible for fruity notes, mostly decreased in the presence of antioxidants. These findings indicate the loss of fruity aromas due to the light exposure $[3,49,50]$, although the white wine used in this study was not characterized by evident floral and fruity notes. Further research will be carried out to clarify this aspect using a more aromatic wine. 


\subsection{Comparison}

When added individually, the three antioxidants had different effectiveness in preventing the development of LST. The relative order was $\mathrm{SO}_{2}>\mathrm{CT}>\mathrm{GSH}$ in $\mathrm{MW}$ and $\mathrm{CT} \geq \mathrm{GSH}>\mathrm{SO}_{2}$ in WW. Therefore, the attempt made to understand the role of the different antioxidants when used in combination by Principal Component Analysis (PCA) was carried out for the two systems (MW and WW) separately. All the parameters investigated in this study were included.

In case of MW, PC1 and PC2 together explained $68 \%$ of variance and the samples were clustered as (i) $\mathrm{MW}, \mathrm{MW}+\mathrm{GSH}$, (ii) $\mathrm{MW}+\mathrm{SO}_{2}, \mathrm{MW}+\mathrm{SO}_{2}+\mathrm{GSH}$, (iii) $\mathrm{MW}+\mathrm{CT}, \mathrm{MW}+\mathrm{CT}+\mathrm{SO}_{2}$, $\mathrm{MW}+\mathrm{CT}+\mathrm{GSH}$ and (iv) $\mathrm{MW}+\mathrm{CT}+\mathrm{SO}_{2}+\mathrm{GSH}$ (Figure 2). The use of $\mathrm{GSH}$ alone led to a small difference in comparison to $\mathrm{MW}$, while $\mathrm{CT}$ alone seemed to play its protective role in a manner similar to that achieved when combined with $\mathrm{SO}_{2}$ or GSH.

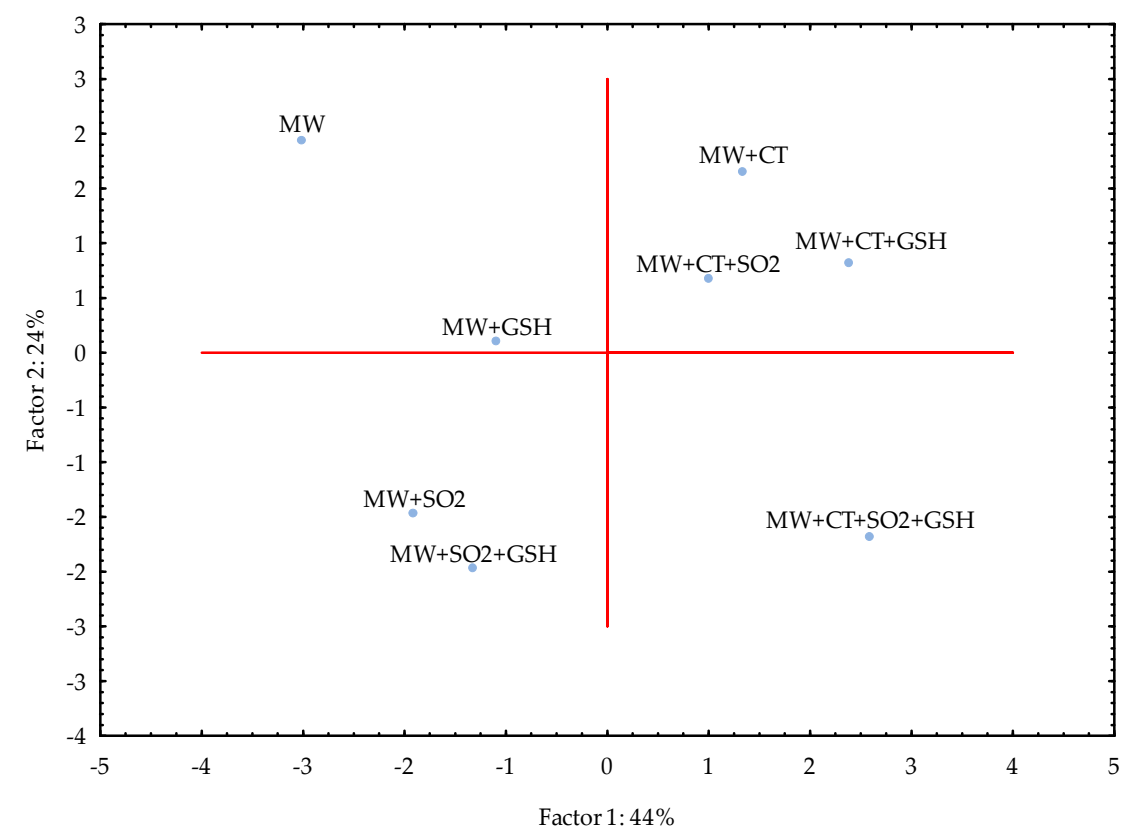

Figure 2. Principal Component Analysis (PCA) for the model wine solution (MW) stored in the dark after the light exposure. For samples coding refer to Table 6. Legend: $\mathrm{SO}_{2}$, sulfur dioxide (20 mg/L), GSH, glutathione (50 mg/L), CT, chestnut tannins (50 mg/L).

PC1 and PC2 together explained $64 \%$ of the variance for WW samples that resulted clustered as follows: (i) $\mathrm{WW}$, (ii) $\mathrm{WW}+\mathrm{SO}_{2}$, (iii) $\mathrm{WW}+\mathrm{CT}, \mathrm{WW}+\mathrm{CT}+\mathrm{SO}_{2}, \mathrm{WW}+\mathrm{GSH}$, (iv) $\mathrm{WW}+\mathrm{SO}_{2}+\mathrm{GSH}, \mathrm{WW}+\mathrm{CT}+\mathrm{GSH}$ and (v) $\mathrm{WW}+\mathrm{CT}+\mathrm{SO}_{2}+\mathrm{GSH}$ (Figure 3). It appears evident that the addition of all the three antioxidants made the WW sample clearly distinguishable from the other samples, as it was found for MW samples. Both CT and GSH alone led to similar evolution of WW; moreover, when GSH was used with either $\mathrm{SO}_{2}$ or $\mathrm{CT}$, the evolution of LST in white wine could occur in a similar way, as it was observed for MW.

The study was carried out in both model wine and white wine due to the complexity of the latter. A very simple model wine was thus designed to avoid interferences and accurately follow the light-induced reactions of RF and Met in the presence of selected antioxidants. With the exception of the addition of $\mathrm{SO}_{2}$ and $\mathrm{CT}+\mathrm{GSH}$, the treatments led to comparable results in both MW and WW as showed by the respective PCA (Figures 2 and 3). Even if in WW the intensity of LST differed in comparison to MW, the effectiveness of $\mathrm{CT}$ alone and in combination with $\mathrm{SO}_{2}$ and $\mathrm{SO}_{2}+\mathrm{GSH}$ was evidenced for the white wine used in the study under our experimental conditions. 


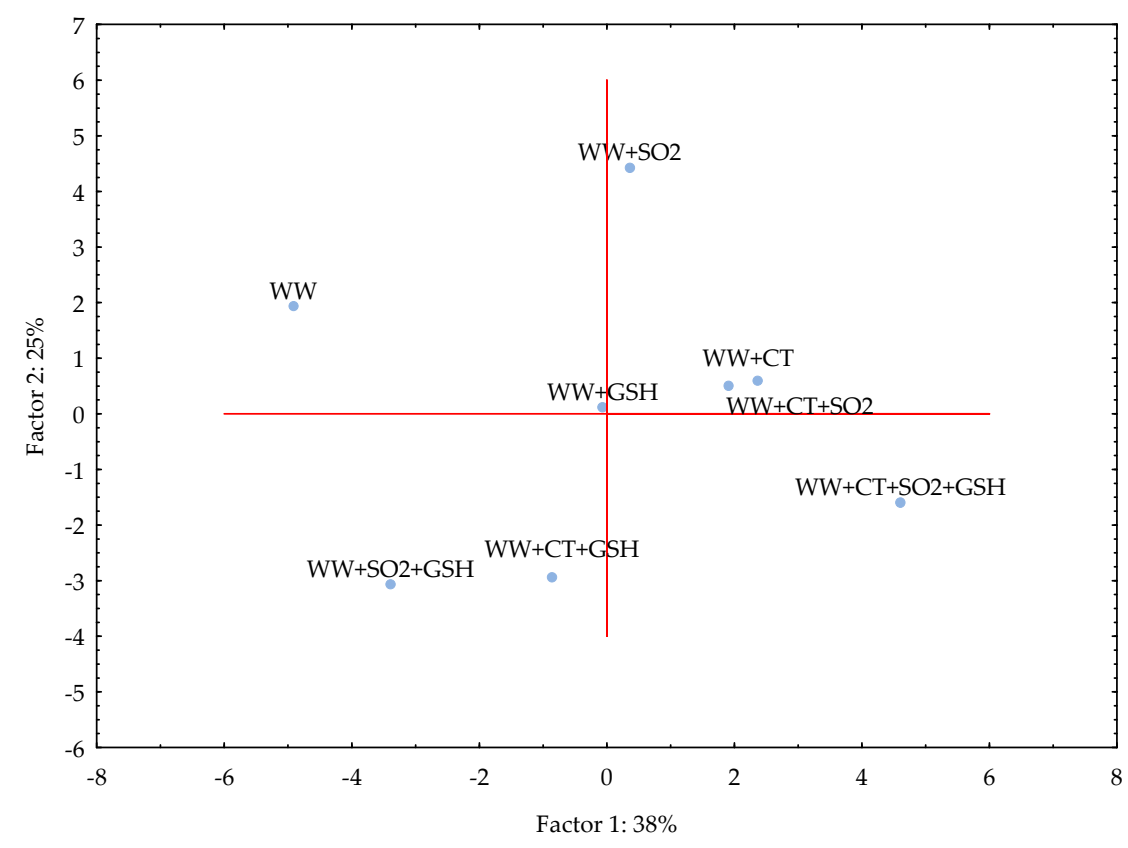

Figure 3. Principal Component Analysis (PCA) for the white wine (WW) stored in the dark after the light exposure. For samples coding refer to Table 6. Legend: $\mathrm{SO}_{2}$, sulphur dioxide $(20 \mathrm{mg} / \mathrm{L}), \mathrm{GSH}$, glutathione (50 mg/L), CT, chestnut tannins (50 mg/L).

\section{Materials and Methods}

\subsection{Chemicals and Reagents}

Methanol, ethanol, acetonitrile, dichloromethane, riboflavin, citric acid, tartaric acid, boric acid, mercaptoethanol, o-phtaldehyde (OPA), amino acid multi standard (containing acidic, neutral, and basic amino acids), riboflavin (RF), $\mathrm{d}_{6}$-dimethyl sulphide $\left(\mathrm{d}_{6}\right.$ DMS), isopropyl disulphide, dimethyl disulphide (DMDS), dimethyl trisulphide (DMTS), p-benzoquinone (pBQ), 3-mercaptopropanoic acid (3MPA), glutathione, trifluoroacetic acid and hydrochloric acid were purchased from Sigma-Aldrich (St. Louis, MO, USA). Sodium metabisulfite was purchased from J.T. Baker (Deventer, The Netherlands). All the chemicals were of analytical grade, at least. HPLC grade water was obtained by a Milli-Q system (Millipore Filter Corp., Bedford, MA, USA).

Commercial hydrolysable tannins from chestnut wood intended for oenological use were provided by Dal Cin (Concorezzo, Italy).

The model wine solution (MW) was made of $5.0 \mathrm{~g} / \mathrm{L}$ tartaric acid and $12 \%$ ethanol $(v / v)$, adjusted to $\mathrm{pH} 3.2$ with sodium hydroxide (Merck, Darmstadt, Germany).

The white wine $\left(\mathrm{WW}_{0}\right)$ produced with Trebbiano grape in vintage 2016 was collected at a local winery just after bottling and analyzed. The concentration of Met in $\mathrm{WW}_{0}$ was $5.90 \pm 0.35 \mathrm{mg} / \mathrm{L}$ and that of total $\mathrm{SO}_{2}$ was $80 \pm 2 \mathrm{mg} / \mathrm{L}$, while no RF nor GSH were detected.

\subsection{Experimental Plan}

The experimental plan consisted of assessing the effect of different additives on the evolution of wine (i) stored in the dark or (ii) exposed to light for $2 \mathrm{~h}$ and then stored in the dark. Both MW and WW, added with RF $(200 \mu \mathrm{g} / \mathrm{L})$ and Met $(4 \mathrm{mg} / \mathrm{L})$, were considered. The three tested additives were $\mathrm{SO}_{2}(20 \mathrm{mg} / \mathrm{L}), \mathrm{GSH}(50 \mathrm{mg} / \mathrm{L})$ and CT $(50 \mathrm{mg} / \mathrm{L})$, added individually or in different combinations for a total of 8 trials for MW and 8 trials for WW. $\mathrm{WW}_{0}$ without the addition of RF and Met was also considered (Table 6). 
Table 6. Experimental plan and sample coding according to treatment.

\begin{tabular}{|c|c|c|}
\hline \multicolumn{2}{|c|}{ Sample Coding } & \multirow{2}{*}{ Antioxidant(s) Added } \\
\hline Model Wine (MW) & White Wine (WW) & \\
\hline- & $\mathrm{WW}_{0}$ & No addition \\
\hline MW & WW & No antioxidant added \\
\hline $\mathrm{MW}+\mathrm{SO}_{2}$ & $\mathrm{WW}+\mathrm{SO}_{2}$ & Sulfur dioxide \\
\hline $\mathrm{MW}+\mathrm{GSH}$ & $\mathrm{WW}+\mathrm{GSH}$ & Glutathione \\
\hline $\mathrm{MW}+\mathrm{SO}_{2}+\mathrm{GSH}$ & $\mathrm{WW}+\mathrm{SO}_{2}+\mathrm{GSH}$ & Sulfur dioxide/Glutathione \\
\hline $\mathrm{MW}+\mathrm{CT}$ & $\mathrm{WW}+\mathrm{CT}$ & Chestnut tannins \\
\hline $\mathrm{MW}+\mathrm{CT}+\mathrm{SO}_{2}$ & $\mathrm{WW}+\mathrm{CT}+\mathrm{SO}_{2}$ & Chestnut tannins/Sulfur dioxide \\
\hline $\mathrm{MW}+\mathrm{CT}+\mathrm{GSH}$ & $\mathrm{WW}+\mathrm{CT}+\mathrm{GSH}$ & Chestnut tannins/Glutathione \\
\hline $\mathrm{MW}+\mathrm{CT}+\mathrm{SO}_{2}+\mathrm{GSH}$ & $\mathrm{WW}+\mathrm{CT}+\mathrm{SO}_{2}+\mathrm{GSH}$ & Chestnut tannins/Sulfur dioxide/Glutathione \\
\hline
\end{tabular}

The codes "MW" and "WW" indicate the model wine solution and white wine, respectively, added with riboflavin and methionine.

In order to perform exposure to light under standardized conditions, MW and WW were placed in clear glass bottles $(100 \mathrm{~mL})$ that were hermetically sealed without headspace and exposed for $2 \mathrm{~h}$ to fluorescent light bulbs emitting 3172 Lumen at $6500 \mathrm{~K}$, with high emission in the absorption wavelengths of RF (370 and $440 \mathrm{~nm}$ ). A laboratory-made lightning device was used, consisting of three fluorescence light bulbs, placed $40 \mathrm{~cm}$ from each other. Each bottle was positioned between two light bulbs, i.e., at a $20 \mathrm{~cm}$ distance [17]. The light-exposed bottles were then stored at $18 \pm 2{ }^{\circ} \mathrm{C}$ in the dark for 24 months. The same sample sets of both MW and WW, not light-exposed, were kept in the dark at identical conditions, as a control.

The concentration of RF, GSH, Met, volatile sulphur compounds (VSCs), i.e., methanethiol (MeSH), DMDS and DMTS, were determined. Two oxidation compounds from Met, namely methionine sulfoxide (Met sulfoxide) and methionine sulfone (Met sulfone), were quantified in MW samples. The total polyphenol index (TPI) and absorbance at $420 \mathrm{~nm}$ were assessed only in MW samples containing CT and in all the WW samples. Additionally, the flavonoids, free amino acid profile, sotolon and the overall volatile profile were analyzed in WW samples. The sensory analysis was carried out for all the trials in both MW and WW for the samples light exposed and kept protected against the light.

\subsection{Determination of Riboflavin}

The method reported by Fracassetti et al. [51] was applied for the measurement of RF content with some modifications [17]. Briefly, sample solutions were passed through a $0.22-\mu \mathrm{m}$ PVDF filter (Millipore, Billerica, MA, USA) and $50 \mu \mathrm{L}$ aliquot was injected in an Acquity HClass UPLC (Waters, Milford, MA, USA) system equipped with a photo diode array detector 2996 (Waters). The detection wavelength was $440 \mathrm{~nm}$. The separation was carried out with (solvent A) 90\% $50 \mathrm{mmol}$ citrate buffer at $\mathrm{pH} 2.5$ and $10 \%$ methanol $(v / v)$ and (solvent B) $10 \% 50 \mathrm{mmol}$ citrate buffer at $\mathrm{pH} 2.5$ and $90 \%$ methanol $(v / v)$ in gradient mode $(70 \% \mathrm{~B}$ in $8 \mathrm{~min})$ at a flow rate of $0.6 \mathrm{~mL} / \mathrm{min}$. Calibration curves were obtained for RF concentrations in the range 10-500 $\mu \mathrm{g} / \mathrm{L}$. Data acquisition and processing were performed by Empower 2 software (Waters).

\subsection{Determination of Glutathione and Cysteine}

Glutathione and cysteine (Cys) were determined by derivatization with $p$-benzoquinone (pBQ) [29]. Briefly, MW and WW samples $(2 \mathrm{~mL})$ were derivatized with pBQ $(100 \mu \mathrm{L}$, $8 \mathrm{mM})$ followed by the addition of 3MPA $(1 \mathrm{~mL}, 1.5 \mathrm{M})$. The reaction mix was filtered through a $0.22 \mu \mathrm{m}$ pore-size PVDF membrane (Millipore, Billerica, MA, USA) and analyzed by an Acquity HClass UPLC (Waters) system equipped with a photo diode array detector 2996 (Waters) using a phenyl-hexyl column $(250 \times 4.6 \mathrm{~mm}, 5$ m, $110 \AA$, Phenomenex, Torrance, CA, USA). The separation was carried out with (solvent A) water/trifluoroacetic acid $0.05 \%(v / v)$ and (solvent B) methanol in gradient mode (from $10 \%$ B to $35 \%$ B in 
$18 \mathrm{~min}$ ) at a flow rate of $1 \mathrm{~mL} / \mathrm{min}$ [29]. The detection wavelength was $303 \mathrm{~nm}$; data acquisition and processing were performed by Empower 2 software (Waters).

\subsection{Determination of Volatile Sulphur Compounds and Other Volatile Compounds}

The analysis of volatile sulfur compounds (VSCs) was performed by Solid Phase Micro Extraction (SPME)-GC/MS following the method described by Fracassetti et al. [17]. Duplicate injections were carried out for each sample. Results are expressed as the relative concentration $(\mu \mathrm{g} / \mathrm{L})$ for MeSH referred to as $\mathrm{d}_{6}$-DMS; DMDS and DMTS amounts were determined by the external standard method $(0.5-100 \mu \mathrm{g} / \mathrm{L})$. The Odor Activity Values (OAVs) were determined as the ratio between the amount of the VSC found in the sample and the respective perception threshold. The perception threshold concentrations considered were as follows: MeSH, $0.3 \mu \mathrm{g} / \mathrm{L}$ in MW and 2-10 $\mu \mathrm{g} / \mathrm{L}$ in WW; DMDS, 20-45 $\mu \mathrm{g} / \mathrm{L}$; DMTS, $0.1 \mathrm{ug} / \mathrm{L}$ [12]. The ratio between the moles of sulfur compounds formed, obtained by summing MeSH, DMDS and DMTS concentrations, and the moles of sulfur lost as degraded Met was calculated.

For the WW samples, the overall profiles of volatile compounds (VOCs) were further evaluated. VOCs were identified according to the NIST library and for an R match higher than $95 \%$ [52]. Data are expressed as the ratio between the area value found in $\mathrm{WW}_{0}$, set equal to 1 , and in samples submitted to the different treatments as labelled in Table 6.

\subsection{Determination of Methionine, Methionine Sulfoxide and Methionine Sulfone}

Methionine, Met sulfoxide and Met sulfone concentrations were quantified in MW samples by UPLC as o-phthalaldehyde (OPA) derivatives under the conditions described by Fracassetti et al. [17] with some modifications. The derivatization solution was prepared in a $10 \mathrm{~mL}$ volumetric flask by dissolving $250 \mathrm{mg}$ of OPA in $1.5 \mathrm{~mL}$ of ethanol, adding $200 \mu \mathrm{L}$ of 2-mercaptoethanol, and making up to the volume with borate buffer $0.4 \mathrm{M}$ at $\mathrm{pH}$ 10.5. The pre-column derivatization was performed as follows: $500 \mu \mathrm{L}$ of borate buffer $0.4 \mathrm{M}$ at pH 10.5 were added with $200 \mu \mathrm{L}$ of sample and $100 \mu \mathrm{L}$ of OPA solution; the reaction mixture was vortexed for $2 \mathrm{~min}$ and $640 \mu \mathrm{L}$ of phosphoric acid $1.5 \%(v / v)$ were added [36]. The reaction mixture was filtered with $0.22 \mu \mathrm{m}$ PVDF filers (Millipore) and injected. The chromatographic separation of OPA derivatives was carried out using an Acquity HClass UPLC (Waters) system equipped with a photo diode array detector 2996 (Waters). The column was a Nova-Pak C18 $(150 \mathrm{~mm} \times 3.9 \mathrm{~mm}$ column, $4 \mu \mathrm{m}$ particle size stationary phase) (Waters) maintained at $40^{\circ} \mathrm{C}$. The solvents were (solvent A) citrate buffer $10 \mathrm{mM}$ at $\mathrm{pH} 7.5$ and (solvent $\mathrm{B}$ ) acetonitrile/methanol/water in proportion 45/45/10 $(v / v / v)$. The separation was carried out at $1 \mathrm{~mL} / \mathrm{min}$ in gradient mode in which $\mathrm{B}$ was from $5 \%$ to $47 \%$ in $22 \mathrm{~min}$. The detection wavelength was $338 \mathrm{~nm}$. The concentrations of Met, Met sulfoxide and Met sulfone were determined by the external standard method (0.1-5 mg/L). Data acquisition and processing were performed by Empower 2 software (Waters).

\subsection{Determination of the Free Amino Acidic Profile}

Free amino acids were quantified in WW samples according to the method of Fracassetti et al. [20] with some modifications by using an Acquity HClass UPLC (Waters) system equipped with a photo diode array detector 2996 (Waters). The pre-column derivatization procedure was performed as follows: $750 \mu \mathrm{L}$ of borate buffer $0.4 \mathrm{M}$ at $\mathrm{pH} 10.5$ were added with $300 \mu \mathrm{L}$ of sample and $150 \mu \mathrm{L}$ of OPA solution. The reaction mixture was vortexed for $2 \mathrm{~min}$, filtered through a $0.22 \mu \mathrm{m}$ PVDF filer (Millipore) and injected. The OPA-derivatized amino acids were separated in a Kinetex Phenyl-Hexyl, $150 \mathrm{~mm} \times 4.6 \mathrm{~mm}$ column, with $2.6 \mu \mathrm{m}$ particle size (Phenomenex) maintained at $50^{\circ} \mathrm{C}$. Eluting solvents were (solvent A) citrate buffer $10 \mathrm{mM}$ at $\mathrm{pH} 7.5$ and (solvent B) acetonitrile/methanol/citrate buffer $10 \mathrm{mM}$ at $\mathrm{pH} 7.5$ in proportion $45 / 45 / 10(v / v / v)$. The separation was carried out at $1 \mathrm{~mL} / \mathrm{min}$ in gradient mode operating as follows: $5 \%$ B for $3 \mathrm{~min}$; from $5 \%$ to $15 \% \mathrm{~B}$ at $6.5 \mathrm{~min}$; from $15 \%$ to $20 \% \mathrm{~B}$ at $9 \mathrm{~min}$; from $20 \%$ to $30 \% \mathrm{~B}$ at $12 \mathrm{~min}$; from $30 \%$ to $40 \%$ at $15.5 \mathrm{~min}$; from $40 \%$ to $80 \%$ at $23 \mathrm{~min}$. The detection wavelength was $338 \mathrm{~nm}$. Amino acids, namely Met, aspartic 
acid, glutamic acid, asparagine, serine, glutamine, histidine, threonine, arginine, alanine, tyrosine, valine, phenylalanine, isoleucine, leucine, ornithine and lysine, were identified and determined by the external standard method $(0.1-20 \mathrm{mg} / \mathrm{L})$. Data acquisition and processing were performed by Empower 2 software (Waters).

\subsection{Determination of Total Flavonoids, Total Phenol Index and Absorbance at $420 \mathrm{~nm}$}

Total flavonoids, total phenol index and absorbance at $420 \mathrm{~nm}$ were determined in all WW samples and in MW samples where CT was added.

For the assessment of total flavonoid content, the samples were properly diluted with a hydrochloric ethanol solution (ethanol/water/hydrochloric acid 37\%, 70/30/1 $v / v / v$ ) in order to obtain an absorption value lower than $1 \pm 0.05 \mathrm{AU}$ at $280 \mathrm{~nm}$. The absorption spectra of the sample were recorded in the wavelength range 700-230 nm and the quantification of flavonoids was carried out according to Corona et al. [53]. The results are expressed as $\mathrm{mg}$ catechin/L, taking into account the derivative of the peak registered at $280 \mathrm{~nm}$ and the molar extinction coefficient of catechin in hydrochloric ethanol.

Total phenol index (TPI) was measured based on the absorption value at $280 \mathrm{~nm}$ after proper dilution of the sample with water in order to obtain an absorption value lower than $1 \pm 0.05 \mathrm{AU}$ at $280 \mathrm{~nm}$. TPI was calculated by multiplying the absorbance value at 280 for the dilution factor [54,55].

The absorption values at $420 \mathrm{~nm}$ were considered in order to estimate the impact of the tested additives on yellow color/browning [56].

\subsection{Determination of Sotolon}

Sotolon was measured in WW samples following the preparation described by Gabrielli et al. [57]. Briefly, $3 \mathrm{~g}$ of $\mathrm{NaCl}$ were dissolved in $30 \mathrm{~mL}$ wine in a 100-mL bottle, then $40 \mathrm{~mL}$ of dichloromethane (DCM) were added. The bottle was hermetically closed and shaken for $10 \mathrm{~min}$ with a wrist action stirrer (Griffin Flask Shaker). The mixture was centrifuged 5 min at $5000 \times g$ and the DCM was separated by a separatory funnel and recovered. The solvent extraction procedure was carried out three times. Eventually, the three organic solvent fractions were jointly collected and added with $2 \mathrm{~g}$ of anhydrous sodium sulfate. DCM was evaporated under vacuum, then the dry material was dissolved into $2 \mathrm{~mL}$ of methanol 5\%, which was purified by a PVPP $50 \mathrm{mg}$ SPE cartridge and the eluted solution was recovered. The quantification of sotolon was carried out by UPLC-UV [57].

\subsection{Sensory Analysis}

A panel constituted by nine expert judges ( 5 males, 4 females, aged 25-55) carried out the olfactory scoring for the "cooked cabbage" descriptor. The score ranged from 1 (not perceived) to 9 (extremely perceived). The panelists were firstly trained using MW samples spiked with Met $(4 \mathrm{mg} / \mathrm{L})$ and two different levels of RF $(200 \mu \mathrm{g} / \mathrm{L}$ or $400 \mu \mathrm{g} / \mathrm{L})$ and exposed to light for two hours using the above-described illuminating device (Section 3.2) in order to make the judges confident about the perception of cooked cabbage note. Sniffing sessions were then carried out using WW samples (Met $4 \mathrm{mg} / \mathrm{L}$, RF $200 \mu \mathrm{g} / \mathrm{L}$ and $400 \mu \mathrm{g} / \mathrm{L}$, light exposure for two hours). The judges were calibrated by sniffing MW solutions spiked with Met $(4 \mathrm{mg} / \mathrm{L})$ and RF $(200 \mu \mathrm{g} / \mathrm{L})$ exposed to light for increasing time up to two hours. Each MW and WW sample was evaluated just after the bottle opening and served at temperature $18 \pm 2{ }^{\circ} \mathrm{C}$.

\subsection{Statistical Analysis}

The statistical analysis was performed with SPSS Win 12.0 program (SPSS Inc., Chicago, IL, USA). One-way ANOVA was carried out to determine the significant differences related to chemical parameters and sensory analysis. Significant differences were judged by a post-hoc Fischer LSD $(p<0.05)$. The principal component analysis (PCA) was performed with Statistica 12 software (Statsoft Inc., Tulsa, OK, USA) on auto-scaled data for an 
overall overview of the effect due to the different additives added and their combination considering the chemical parameters and the sensory data.

\section{Conclusions}

The use of additives against the appearance of LST in white wine is a crucial aspect in wine technology since a variety of oenological strategies exists potentially counteracting the sensory modifications after bottling. Therefore, understanding the mechanisms behind each of these is of utmost interest. For this reason, the photo-induced mechanisms were investigated in a model solution. This approach allows the easier interpretation of chemical pathways taking place in wine since interfering reactions could be avoided.

The hydrolysable tannins showed to have a protective effect against the formation of LST in the white wine adopted in this study. Nonetheless, the intensity of LST differed in the tested white wine in comparison to model wine. The prevention of LST by means of hydrolysable tannins, alone and in combination with $\mathrm{SO}_{2}$, was found in both the matrices investigated, supporting the capability of tannins to counteract the formation of LST. The simultaneous addition of tannins and $\mathrm{SO}_{2}$ produced a different effect than $\mathrm{CT}$ alone. These results suggest that a higher addition of $\mathrm{SO}_{2}$ could not prevent LST in white wine, but, on the contrary, it could favor the VSC-dependent spoilage. Differently, the use of hydrolysable tannins prior to bottling could be an effective oenological approach to limit the occurrence of LST. The combined use of other antioxidants (i.e., $\mathrm{SO}_{2}+\mathrm{GSH}$ ) can be also effective.

Future perspectives will be to evaluate LST formation in white wines produced under an industrial scale with hydrolysable tannins added at bottling. Their addition will be investigated in other white wines, both still and sparkling, and rosé wines to further evidence their capability against LST.

Author Contributions: Conceptualization, D.F. and A.T.; methodology, D.F. and N.M.; software, D.F.; formal analysis, N.M.; investigation, D.F. and N.M.; resources, D.F. and A.T.; data curation, D.F.; writing—original draft preparation, D.F. and N.M.; writing—review and editing, S.L., L.P. and A.T.; funding acquisition, D.F., S.L. and A.T. All authors have read and agreed to the published version of the manuscript.

Funding: The study was supported by European Agricultural Fund for Rural Development (Enofotoshield project; D.d.s. 1 luglio 2019-n. 9551, B.U. R.L. Serie Ordinaria n. 27-04 luglio 2019) and Piano di Sostegno alla Ricerca 2017-2018-Linea 2-Università degli Studi di Milano.

Institutional Review Board Statement: Not applicable.

Informed Consent Statement: Not applicable.

Data Availability Statement: Not applicable.

Acknowledgments: The authors are grateful to Andrea Baratti for his technical support.

Conflicts of Interest: The authors declare no conflict of interest.

Sample Availability: Not available. 


\section{Appendix A}
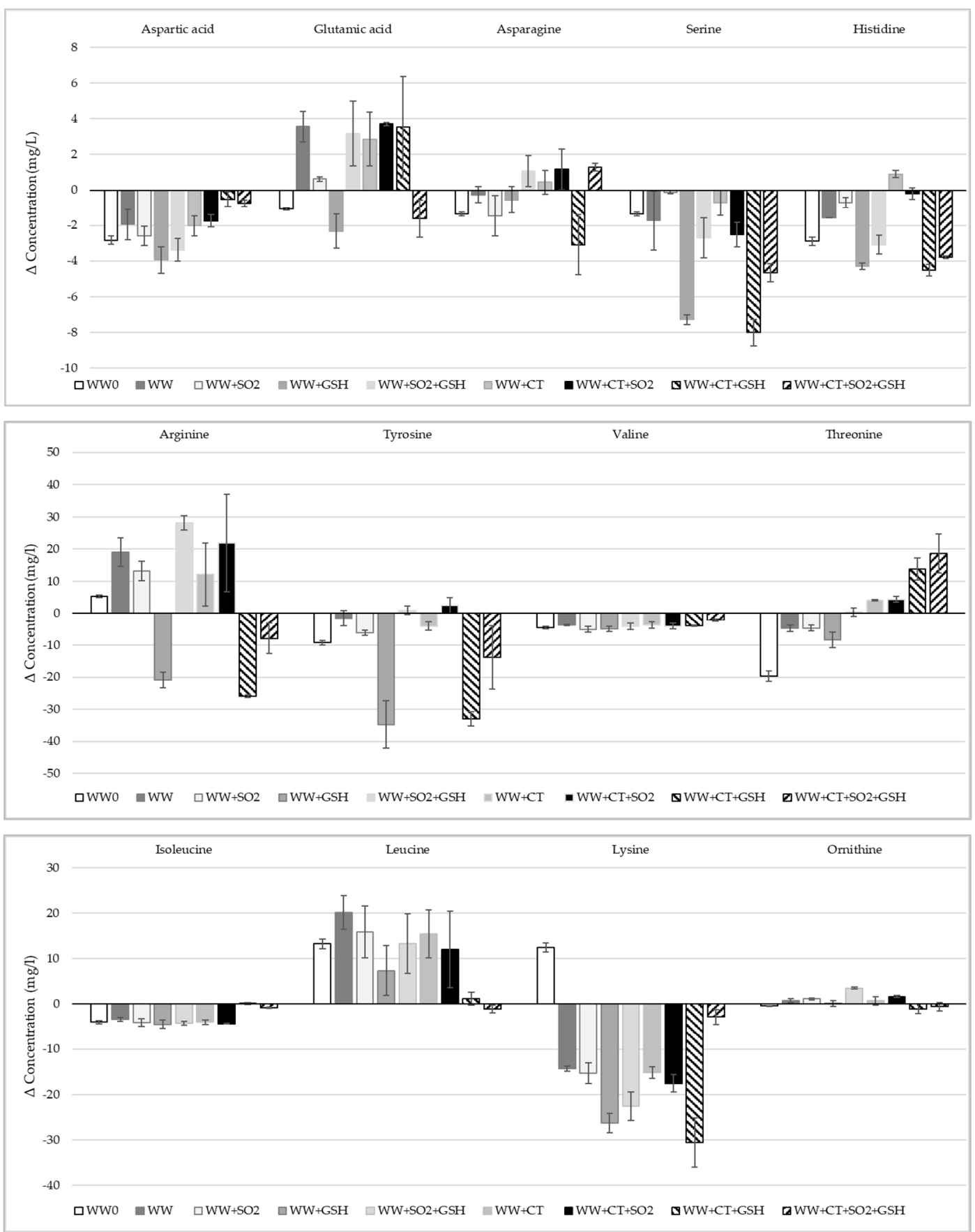

Figure A1. Differences of the amino acid concentrations between the white wine (WW) samples without light exposure and the corresponding WW samples with light exposure. For samples coding, see Table 6. Data are not shown for alanine, glutamine and phenylalanine as negligible differences were found. 

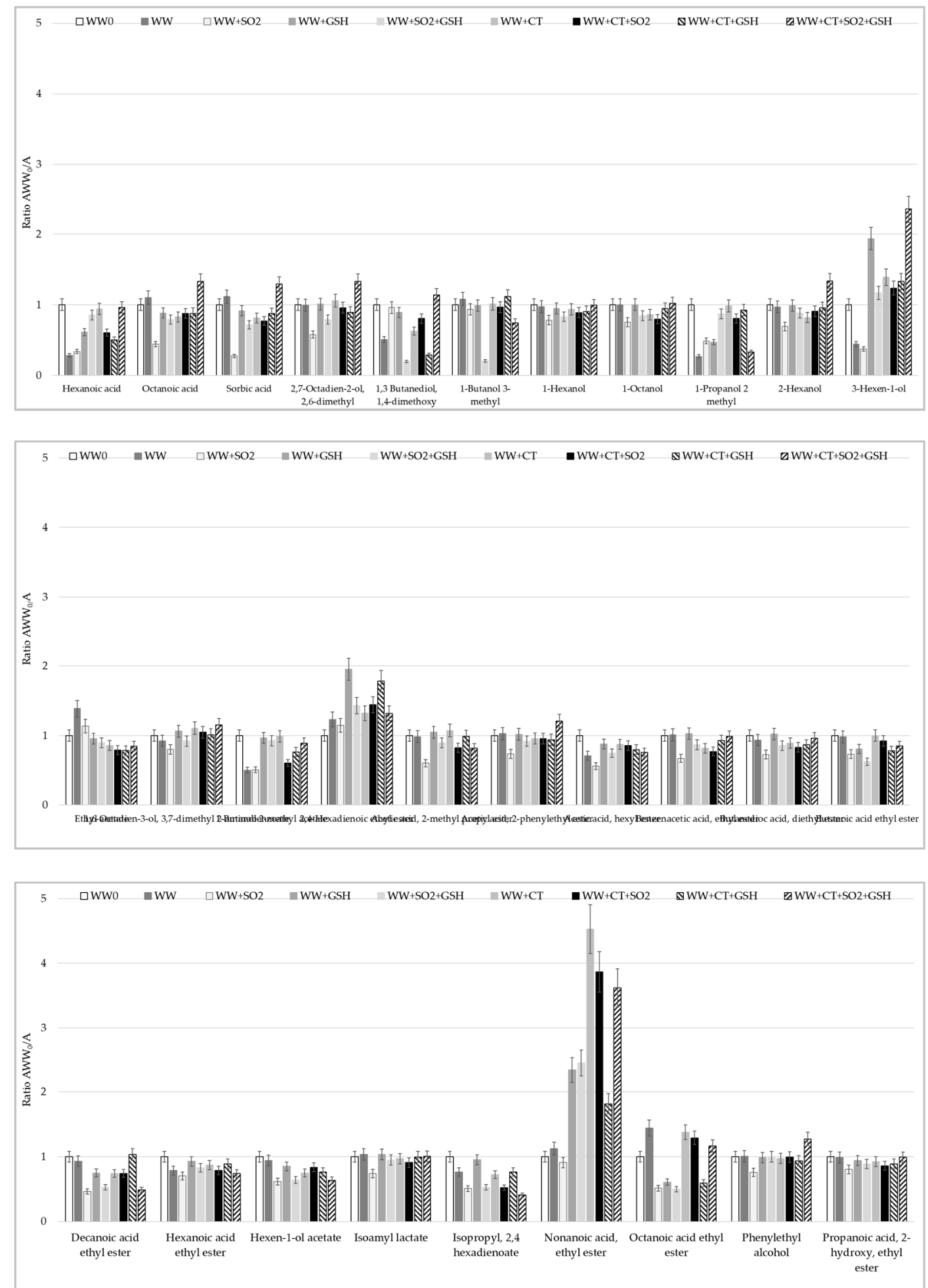

Figure A2. Volatile compound profiles determined in white wine (WW) samples exposed to light prior the storage in the dark. $W_{0}$ sample (glutathione- and riboflavin-free white wine, no Met added) was fixed as 1 and the ratio among it and WW samples with the tested additives were calculated. For samples coding see Table 6.

\section{References}

1. Bekbölet, M. Light effects on food. J. Food Prot. 1990, 53, 430-440. [CrossRef]

2. Clark, A.C.; Dias, D.A.; Smith, T.A.; Ghiggino, K.P.; Scollary, G.R. Iron III tartrate as a potential precursor of light-induced oxidative degradation of white wine: Studies in a model wine system. J. Agric. Food Chem. 2011, 59, 3575-3581. [CrossRef] [PubMed] 
3. D'Auria, M.; Emanuele, L.; Racioppi, R. The effect of heat and light on the composition of some volatile compounds in wine. Food Chem. 2009, 117, 9-14. [CrossRef]

4. Maujean, A.; Haye, M.; Feuillat, M. Contribution à l'étude des "goûts de lumière" dans le vin de Champagne. II. Influence de la lumière sur le potentiel d'oxydoreduction. Correlation avec la teneur en thiols du vin. OENO One 1978, 12, 277-290. [CrossRef]

5. Maujean, A.; Seguin, N. Contribution à l'étude des goûts de lumière dans les vins de Champagne. 3. Les réactions photochimiques responsables des goûts de lumière dans le vin de Champagne. Sci. Aliment. 1983, 3, 589-601.

6. Foote, C.S. Photosensitized oxidation and singlet oxygen: Consequences in biological systems. In Free Radicals in Biology; Pryor, W.A., Ed.; Academic Press: New York, NY, USA, 1976; Volume 2, pp. 85-133.

7. Cardoso, D.R.; Libardi, S.H.; Skibsted, L.H. Riboflavin as a photosensitizer. Effects on human health and food quality. Food Funct. 2012, 3, 487-502. [CrossRef]

8. Sheraz, M.A.; Kazi, S.H.; Ahmed, S.; Anwar, Z.; Ahmad, I. Photo, thermal and chemical degradation of riboflavin. Beilstein J. Org. Chem. 2014, 10, 1999-2012. [CrossRef] [PubMed]

9. Fracassetti, D.; Di Canito, A.; Bodon, R.; Messina, N.; Vigentini, I.; Foschino, R.; Tirelli, A. Light-struck taste in white wine: Reaction mechanisms, preventive strategies and future perspectives to preserve wine quality. Trends Food Sci. Technol. 2021, 112, 547-558. [CrossRef]

10. Asaduzzaman, M.; Scampicchio, M.; Biasioli, F.; Bremer, P.J.; Silcock, P. Methanethiol formation during the photochemical oxidation of methionine-riboflavin system. Flavour Fragr. J. 2020, 35, 34-41. [CrossRef]

11. Maujean, A.; Seguin, N. Contribution à l'étude des goûts de lumière dans les vins de Champagne. 4. Approaches a une solution œnologique des moyens de prévention des goûts de lumière. Sci. Aliment. 1983, 3, 603-613.

12. Fracassetti, D.; Vigentini, I. Occurrence and analysis of sulfur compounds in wine. In Grapes and Wines-Advances in Production, Processing, Analysis and Valorization; InTechOpen: London, UK, 2017; pp. 225-251. Available online: https://www.intechopen. com/chapters/58638 (accessed on 30 August 2021).

13. Grant-Preece, P.; Barril, C.; Schmidtke, L.M.; Scollary, G.R.; Clark, A.C. Light-induced changes in bottled white wine and underlying photochemical mechanisms. Crit. Rev. Food Sci. Nutr. 2017, 57, 743-754. [CrossRef]

14. Grant-Preece, P.; Barril, C.; Leigh, M.; Schmidtke, L.M.; Clark, A.C. Impact of fluorescent lighting on the browning potential of model wine solutions containing organic acids and iron. Food Chem. 2018, 243, 239-248. [CrossRef]

15. Pichler, U. Analisi della riboflavina nei vini bianchi e influenza della sua concentrazione. L'Enotecnico 1996, 32, 57-62.

16. Mattivi, F.; Monetti, A.; Vrhovsek, U.; Tonon, D.; Andrés-Lacueva, C. High-performance liquid chromatographic determination of the riboflavin concentration in white wines for predicting their resistance to light. J. Chromatogr. A 2000, 888, 121-127. [CrossRef]

17. Fracassetti, D.; Limbo, S.; Pellegrino, L.; Tirelli, A. Light-induced reactions of methionine and riboflavin in model wine: Effects of hydrolysable tannins and sulfur dioxide. Food Chem. 2019, 298, 124952. [CrossRef]

18. Riberau-Gayon, P.; Glories, Y.; Maujean, A.; Dubourdieu, D. Handbook of Enology; John Wiley \& Sons Ltd: Chichester, UK, 2006.

19. Santos, M.A.; García-Ramírez, J.J.; Revuelta, J.L. Riboflavin Biosynthesis in Saccharomyces cerevisiae. J. Biol. Chem. 1995, 270, 437-444. [CrossRef]

20. Fracassetti, D.; Gabrielli, M.; Encinas, J.; Manara, M.; Pellegrino, L.; Tirelli, A. Approaches to prevent the light-struck taste in white wine. Aust. J. Grape Wine Res. 2017, 23, 329-333. [CrossRef]

21. Fracassetti, D.; Tirelli, A.; Limbo, S.; Mastro, M.; Pellegrino, L.; Ragg, E.M. Investigating the role of antioxidant compounds in riboflavin-mediated photo-oxidation of methionine: A 1H-NMR approach. ACS Omega 2020, 5, 26220-26229. [CrossRef] [PubMed]

22. Arapitsas, P.; Dalledonne, S.; Scholz, M.; Catapano, A.; Carlin, S.; Mattivi, F. White wine light-strike fault: A comparison between flint and green glass bottles under typical supermarket conditions. Food Packag. Shelf Life 2020, 24, 100492. [CrossRef]

23. Makhotkina, O.; Kilmartin, P. A Uncovering the influence of antioxidants on polyphenol oxidation in wines using an electrochemical method: Cyclic voltammetry. J. Electroanal. Chem. 2009, 633, 165-174. [CrossRef]

24. Lavigne, V.; Dubourdieu, D. Affinamento sulle fecce e freschezza dei vini bianchi. Vigne Vini 2004, 31, 58-66.

25. Vignault, A.; González-Centeno, M.R.; Pascual, O.; Gombau, J.; Jourdes, M.; Moine, V.; Teissedre, P.-L. Chemical characterization, antioxidant properties and oxygen consumption rate of 36 commercial oenological tannins in a model wine solution. Food Chem. 2018, 268, 210-219. [CrossRef] [PubMed]

26. Ricci, A.; Parpinello, G.P.; Teslić, N.; Kilmartin, P.A.; Versari, A. Suitability of the cyclic voltammetry measurements and DPPH• spectrophotometric assay to determine the antioxidant capacity of food-grade oenological tannins. Molecules 2019, $24,2925$. [CrossRef]

27. Fracassetti, D.; Gabrielli, M.; Costa, C.; Tomás-Barberán, F.A.; Tirelli, A. Characterization and suitability of polyphenols-based formulas to replace sulfur dioxide for storage of sparkling white wine. Food Control. 2016, 60, 606-614. [CrossRef]

28. Fracassetti, D.; Coetzee, C.; Vanzo, A.; Ballabio, D.; du Toit, W.J. Oxygen consumption in South African Sauvignon blanc wines: Role of glutathione, sulphur dioxide and certain phenolics. S. Afr. J. Enol. Vitic. 2013, 34, 156-169. [CrossRef]

29. Fracassetti, D.; Tirelli, A. Monitoring of glutathione concentration during winemaking by a reliable high-performance liquid chromatography analytical method. Aus. J. Grape Wine Res. 2015, 21, 389-395. [CrossRef]

30. Resolution Oeno 446-2015. Treatment of Wine with Glutathione. Available online: https://www.oiv.int/public/medias/1687 / oiv-oeno-446-2015-en.pdf (accessed on 30 July 2021). 
31. Amerine, M.A.; Ough, C.S. Alcohols. In Methods for Analysis of Musts and Wines; Amerine, M.A., Ough, C.S., Eds.; John Wiley and Sons: New York, NY, USA, 1980.

32. Sartor, S.; Burin, V.M.; Caliari, V.; Bordignon-Luiz, M.T. Profiling of free amino acids in sparkling wines during over-lees aging and evaluation of sensory properties. LWT-Food Sci. Technol. 2021, 140, 110847. [CrossRef]

33. Robichaud, J.L.; Noble, A.C. Astringency and bitterness of selected phenolics in wine. J. Sci. Food Agric. 1990, 53, 343-353. [CrossRef]

34. Bitsch, R.; Bitsch, I. HPLC determination of riboflavin in fortified foods. In Fortified foods with Vitamins: Analytical Concepts to Assure Better and Safer Products; Rychlik, M., Ed.; John Wiley and Sons: New York, NY, USA, 2011.

35. Golbach, J.L.; Ricke, S.C.; O’Bryan, C.A.; Crandall, P.G. Riboflavin in nutrition, food processing and analysis—a review. J Food Res. 2014, 3, 23-35. [CrossRef]

36. Barata-Vallejo, S.; Ferreri, C.; Postigo, A.; Chatgilialoglu, C. Radiation chemical studies of methionine in aqueous solution: Understanding the role of molecular oxygen. Chem. Res. in Toxicol. 2010, 23, 258-263. [CrossRef] [PubMed]

37. Inoue, M.; Hayatsu, H. The interactions between bisulfite and amino acids. The formation of methionine sulfoxide from methionine in the presence of oxygen. Chem. Pharm. Bull. 1971, 19, 1286-1289. [CrossRef]

38. Winterbourn, C.C. Revisiting the reactions of superoxide with glutathione and other thiols. Arch. Biochem. Biophys. 2016, 595, 68-71. [CrossRef] [PubMed]

39. Min, D.B.; Boff, J.M. Chemistry and reaction of singlet oxygen in foods. Compr. Rev. Food Sci. Food Saf. 2002, 1, 58-72. [CrossRef]

40. Clark, A.C.; Prenzler, P.D.; Scollary, G.R. Impact of the condition of storage of tartaric acid solution on the production and stability of glyoxylic acid. Food Chem. 2007, 102, 905-916. [CrossRef]

41. Gijs, L.; Perpète, P.; Timmermans, A.; Collin, S. 3-Methylthiopropionaldehyde as precursor of dimethyl trisulfide in aged beers. J. Agric. Food Chem. 2000, 48, 6196-6199. [CrossRef] [PubMed]

42. Câmara, J.S.; Alves, M.A.; Marques, J.C. Changes in volatile composition of Madeira wines during their oxidative ageing. Anal. Chim. Acta 2006, 563, 188-197. [CrossRef]

43. Fracassetti, D.; Tirelli, A. Effetti della composizione del vino rosso sulla cinetica di consumo dell'ossigeno in presenza di tannini enologici. In Proceedings of the 11 Enoforum 2019, Vicenza, Italy, 21-23 May 2019.

44. Danilewicz, J.C. Mechanism of autoxidation of polyphenols and participation of sulfite in wine: Key role of iron. Am. J. Enol Vitic. 2011, 62, 319-328. [CrossRef]

45. Maury, C.; Clark, A.C.; Scollary, G.R. Determination of the impact of bottle colour and phenolic concentration on pigment development in white wine stored under external conditions. Anal. Chim. Acta 2010, 660, 81-86. [CrossRef] [PubMed]

46. Cilliers, J.J.L.; Singleton, V.L. Caffeic acid autoxidation and the effects of thiols. J. Agric. Food Chem. 1990, 38, 1789-1796. [CrossRef]

47. Lavigne, V.; Pons, A.; Darriet, P.; Dubourdieu, D. Changes in the sotolon content of dry white wines during barrel and bottle aging. J. Agric. Food Chem. 2008, 56, 2688-2693. [CrossRef] [PubMed]

48. Guichard, E.; Pham, T.T.; Etiévant, P. Quantitative determination of sotolon in wines by high-performance liquid chromatography. Chromatographia 1993, 37, 539-542. [CrossRef]

49. Benítez, P.; Castro, R.; Natera, R.; García Barroso, C. Changes in the polyphenolic and volatile content of "fino" Sherry wine exposed to high temperature and ultraviolet and visible radiation. Eur. Food Res. Technol. 2006, 222, 302-309. [CrossRef]

50. Díaz, I.; Castro, R.I.; Ubeda, C.; Loyola, R.; Felipe Laurie, V. Combined effects of sulfur dioxide, glutathione and light exposure on the conservation of bottled Sauvignon blanc. Food Chem. 2021, 356, 129689. [CrossRef] [PubMed]

51. Fracassetti, D.; Limbo, S.; D'Incecco, P.; Tirelli, A.; Pellegrino, L. Development of a HPLC method for the simultaneous analysis of riboflavin and other flavin compounds in liquid milk and milk products. Eur. Food Res. Technol. 2018, 244, 1545-1554. [CrossRef]

52. Fracassetti, D.; Camoni, D.; Montresor, L.; Bodon, R.; Limbo, S. Chemical characterization and volatile profile of Trebbiano di Lugana wine: A case study. Foods 2020, 9, 956. [CrossRef]

53. Corona, O.; Squadrito, M.; Vento, G.; Tirelli, A.; Di Stefano, R. Over-evaluation of total flavonoids in grape skin extracts containing sulphur dioxide. Food Chem. 2015, 172, 537-542. [CrossRef]

54. Di Stefano, R.; Cravero, M.C.; Gentilini, N. Metodi per lo studio dei polifenoli dei vini. L'Enotecnico 1989, 5, 83-89.

55. Fracassetti, D.; Gabrielli, M.; Corona, O.; Tirelli, A. Characterisation of Vernaccia Nera (Vitis vinifera L.) grapes and wine. S. Afr. J. Enol. Vitic. 2017, 38, 72-81. [CrossRef]

56. Li, H.; Guo, A.; Wang, H. Mechanisms of oxidative browning of wine. Food Chem. 2008, 108, 1-13. [CrossRef]

57. Gabrielli, M.; Fracassetti, D.; Tirelli, A. UHPLC quantification of sotolon in white wine. J. Agric. Food Chem. 2014, 62, 4878-4883. [CrossRef] 